\title{
REAÇ̃̃̃ DE CULTIVARES E ÉPOCA DE AVALIAÇÃO DA FERRUGEM ALARANJADA DA CANA-DE-AÇÚCAR
}

\author{
REACTION OF COMMERCIAL CULTIVARS AND ASSESSMENT DATE OF \\ ORANGE RUST OF SUGARCANE
}

\section{Ana Claudia KLOSOWSKI ${ }^{1}$; João Carlos BESPALHOK FILHO ${ }^{2}$; Lucimeris RUARO²; Reginaldo Batista FRAGOSO ${ }^{3}$; Louise Larissa MAY DE MIO $^{2}$ \\ 1. Doutoranda do Programa de Pós-Graduação em Agronomia-Produção Vegetal, Departamento de Fitotecnia e Fitossanitarismo - Universidade Federal do Paraná - UFPR, Curitiba, PR, Brasil. ana_clkl@ yahoo.com.br; 2. Professor, Doutor, Departamento de Fitotecnia e Fitossanitarismo - UFPR, Curitiba, PR, Brasil; 3. Mestrando do Programa de Pós-Graduação em Agronomia-Produção Vegetal, Departamento de Fitotecnia e Fitossanitarismo - UFPR, Curitiba, PR, Brasil.}

\begin{abstract}
RESUMO: Os objetivos deste estudo foram avaliar a reação de 28 cultivares de cana-de-açúcar à ferrugem alaranjada, em campo, estabelecendo uma época de avaliação adequada para os programas de melhoramento, e determinar os períodos de incubação e latência, incidência e severidade na cultivar padrão suscetível, em casa-de-vegetação. No campo, a severidade foi avaliada em cana-planta (dez meses) e em cana-soca (três, cinco, sete e nove meses). A partir destes dados, calculou-se a área abaixo da curva de progresso da doença (AACPD). Para estabelecer a época de avaliação adequada, calculou-se a correlação de Pearson entre os resíduos das datas com os da AACPD. Em casa-de-vegetação, inoculou-se a cultivar RB72454 e avaliou-se incidência e severidade. Das cultivares avaliadas, 14 foram suscetíveis à ferrugem alaranjada, sendo discriminadas em quatro grupos de suscetibilidade. A avaliação em maio (cana-soca, aos nove meses), foi a que mais se correlacionou com a AACPD, sendo a época adequada para avaliar a reação de cultivares à doença, no norte do Estado do Paraná. O período de incubação e latência na cultivar padrão suscetível foi de sete e dez dias, respectivamente. A cultivar RB72454 é a única altamente suscetível à ferrugem alaranjada e as demais avaliadas apresentam menores graus de suscetibilidade.
\end{abstract}

PALAVRAS-CHAVE: Puccinia kuehnii. Saccharum spp. Níveis de suscetibilidade. Data de avaliação. Incubação. Latência.

\section{INTRODUÇÃOO}

O Brasil é o maior produtor mundial de cana-de-açúcar (Saccharum spp.) (FAO, 2010), o que faz com que a cana seja considerada um dos principais produtos do agronegócio brasileiro. Atualmente, conta com uma área plantada de mais de oito milhões de hectares e a produção nacional na última safra, 2011/2012, foi superior a 570 milhões de toneladas (CONAB, 2012).

Entre vários fatores limitantes à produção da cultura, destacam-se a ocorrência e a severidade de doenças, que se constituem no principal motivo para a substituição de cultivares, devido ao decréscimo de produtividade que provocam (SANTOS, 2004).

A ferrugem alaranjada da cana-de-açúcar, causada pelo fungo Puccinia kuehnii (W. Krüger) E.J. Butler, foi relatada no Brasil pela primeira vez no ano de 2009, no município de Araraquara, Estado de São Paulo e, atualmente, grandes áreas produtoras nos estados de Mato Grosso do Sul, Minas Gerais, Goiás e Paraná já relataram também sua presença. Estudos recentes apontam que apenas quatro variedades plantadas no Brasil são suscetíveis a doença, porém as diversas condições ambientais observadas no país podem fazer com que esse número aumente rapidamente (Barbasso et al., 2010). Por ser uma doença recentemente descoberta no país, os trabalhos sobre a reação das cultivares brasileiras à doença são escassos.

Os sintomas da ferrugem alaranjada se manifestam na forma de pústulas (urédias) alaranjadas a castanho-alaranjadas no limbo foliar, e, dessa forma, o fungo irá interferir na fotossíntese, comprometendo o desenvolvimento e produtividade da planta e resultando em menor acúmulo de sacarose nos colmos (ZHAO et al., 2011). As pústulas podem estar distribuídas por toda a superfície foliar, porém tendem a estar mais freqüentes na base e meio das folhas (MINCHIO et al., 2011).

Cultivares altamente suscetíveis à ferrugem alaranjada tendem a ser eliminadas dos canaviais e dos programas de melhoramento genético da cultura. No entanto, a reação das cultivares de suscetibilidade intermediária à doença deve ser estudada a fim de avaliar a viabilidade do seu plantio e a sua manutenção em programas de melhoramento, se estas apresentarem características produtivas satisfatórias.

Normalmente, a resistência a doenças na cana-de-açúcar tem caráter quantitativo (ROSSETO; 
SANTIAGO, 2005). A resistência quantitativa é um tipo de resistência parcial, na qual o hospedeiro pode apresentar reação de suscetibilidade, mas verifica-se uma baixa taxa de desenvolvimento da doença (PARLEVLIET, 1979). Decorrente disso, primeiramente é importante conhecer a reação de uma cultivar padrão suscetível para que se tenha um parâmetro de comparação a fim de estabelecer níveis de resistência quantitativa.

O sucesso dos processos de seleção de genótipos nos programas de melhoramento depende de vários fatores, dentre os quais a instalação de experimentos com boa precisão experimental, a escolha correta dos caracteres e épocas de avaliação (GAZAFFI et al., 2010). Por isso é importante que se estabeleça uma época de avaliação da ferrugem alaranjada para os programas de melhoramento que proporcione respostas representativas da suscetibilidade das cultivares.

Com base no contexto descrito, este trabalho teve como objetivos: (i) avaliar a reação de 28 cultivares, dentre as mais plantadas no Estado do Paraná, à ferrugem alaranjada, em campo; (ii) estabelecer a época mais adequada para os programas de melhoramento avaliarem suscetibilidade de cultivares; (iii) verificar períodos de incubação e latência; e (iv) determinar incidência e severidade da ferrugem alaranjada nas folhas da cultivar padrão suscetível, em condições controladas ideais para o desenvolvimento da doença.

\section{MATERIAL E MÉTODOS}

\section{Avaliação da reação de cultivares em campo}

O experimento foi conduzido em campo na Estação Experimental da Universidade Federal do Paraná (UFPR), no município de Paranavaí-PR, sob condições de infecção natural do patógeno. A Estação está situada entre as coordenadas $23^{\circ} 05^{\prime}$ de latitude Sul e $52^{\circ} 26^{\prime}$ de longitude Oeste, com altitude média de $470 \mathrm{~m}$. O solo é classificado como Latossolo Vermelho Distrófico, com relevo suave ondulado. O local apresenta clima tipo Cfa, subtropical, com temperatura média no mês mais frio de $18{ }^{\circ} \mathrm{C}$ e temperatura média no mês mais quente de $22{ }^{\circ} \mathrm{C}$ e precipitação bem distribuída ao longo do ano, não apresentando estação seca definida, conforme a classificação de Köppen.

$\mathrm{O}$ experimento foi conduzido em bloco único por cultivar, em campo já instalado em área homogênea da Estação Experimental. Os blocos foram compostos de seis linhas de $10 \mathrm{~m}$ de comprimento, espaçadas por $1,40 \mathrm{~m}$, sendo as quatro linhas centrais consideradas como parcela útil. Cada linha, na qual se avaliaram cinco plantas, foi considerada uma repetição, totalizando quatro repetições por cultivar. $\mathrm{O}$ experimento foi conduzido em faixas visando minimizar o efeito entre cultivares.

As cultivares avaliadas foram desenvolvidas pelo Programa de Melhoramento Genético da Canade-açúcar (PMGCA) da Rede Interuniversitária para o Desenvolvimento do Setor Sucroalcooleiro (RIDESA) e correspondem às cultivares RB (República do Brasil) mais plantadas no Estado do Paraná. São elas: RB785148, RB835486, RB835054， RB855035， RB855036， RB855453, RB855156， RB865230， RB925211， RB925345, RB946903, RB956911, RB966928, RB986419, RB72454, RB835089, RB845210, RB845257, RB845197, RB855536, RB855546, RB855113, RB867515, RB925268, RB928064, RB835744, RB92579 e RB966229.

Avaliações de severidade foram realizadas em vários estádios, avaliando-se a folha +1 , que corresponde à folha fotossintetizante mais ativa da planta (Silva et al., 2008). A primeira avaliação foi realizada aos nove meses da cana-planta, em meados de julho/2011, antes do primeiro corte. Após este período foram realizadas avaliações aos três (novembro/2011), cinco (janeiro/2012), sete (março/2012) e nove meses (maio/2012) da canasoca. A severidade foi estimada com auxílio da escala diagramática proposta por Klosowski et al. (2013).

\section{Avaliação da cultivar padrão suscetível em condições controladas}

Foi realizado o plantio de 16 mini-toletes contendo uma gema da cultivar RB72454, provenientes da Estação Experimental de Paranavaí, em vasos com capacidade de 4 litros, contendo solo, no mês de março de 2011. As plantas foram mantidas em casa-de-vegetação situada no Setor de Ciências Agrárias, da Universidade Federal do Paraná, em Curitiba-PR, a uma temperatura de 25 ${ }^{\circ} \mathrm{C} \pm 5^{\circ} \mathrm{C}$ com a irrigação ocorrendo duas vezes por dia.

O preparo da suspensão foi realizado com urediniósporos de P. kuehnii, retirados de folhas da cultivar RB72454, provenientes da Estação Experimental de Paranavaí, com auxílio de pincéis. Adicionou-se uma gota de espalhante adesivo, Tween 20 (polioxietilenosorbitano) (Amresco, Solon OH, EUA) a cada $1000 \mathrm{~mL}$ de suspensão e ajustou-se a concentração final para $1 \times 10^{5}$ urediniósporos viáveis $\mathrm{mL}^{-1}$, com auxílio de um hemacitômetro (câmara de Neubauer, Optik Labor, Germany). 
Plantas com 30 dias de idade foram inoculadas por pulverização com $25 \mathrm{~mL}$ da suspensão por planta e mantidas em câmara úmida por 24 horas, feita com plástico umedecido preso ao vaso. A folha +1 foi marcada com barbante para se identificar a posição das folhas no decorrer das avaliações. As plantas foram avaliadas diariamente até o aparecimento das lesões.

Os parâmetros avaliados foram o período de incubação (período de tempo entre a inoculação e o aparecimento de sintomas em 50\% das plantas avaliadas) e latência (período de tempo entre a inoculação e a esporulação das lesões em $50 \%$ das plantas avaliadas), a incidência (número de folhas com lesão em relação ao total de folhas) e a severidade (número de pústulas na área de $5 \mathrm{~cm}^{2}$ ). A posição da área marcada de $5 \mathrm{~cm}^{2}$ variou conforme a folha da planta, pois a incidência das lesões variou nas diferentes folhas. Portanto, nas folhas mais velhas, $+4 \mathrm{e}+3$, a área marcada esteve no terço basal da folha. Já nas folhas +2 e +1 , a área marcada estava posicionada no terço médio da folha, enquanto nas folhas mais novas, 0 e -1 , marcou-se a área no terço apical da folha. As avaliações destes parâmetros foram realizadas a cada cinco dias, sendo que a primeira avaliação ocorreu no dia em que aparecerem as primeiras pústulas. Foram realizadas três avaliações.

\section{Análise de dados}

A partir dos dados de severidade das cultivares nas datas de avaliação em cana-soca calculou-se a área abaixo da curva de progresso da doença (AACPD), somando-se as áreas trapezoidais (CAMPBELL; MADDEN, 1990). Verificou-se se os dados de severidade e AACPD atendiam aos pressupostos da análise de variância por meio do método BOX COX (Box \& Cox, 1964), que sugeriu a transformação raiz cúbica de $(x+0,01)$, para os dados de AACPD, e 1/raiz quadrada de $(x+0,1)$, para os dados de severidade em cana-planta e canasoca. Os dados transformados foram submetidos à análise de variância e as médias, comparadas pelo teste de Scott-Knott, a 5\% de probabilidade.

A fim conhecer a época de avaliação que melhor reflete a suscetibilidade das cultivares, fezse a correlação de Pearson entre os resíduos de cada data de avaliação com os da AACPD (Steel et al., 1997). A correlação foi feita entre os resíduos para não se considerar os efeitos das cultivares.
Foi também realizada uma análise multivariada de agrupamento com o objetivo de agrupar genótipos semelhantes quanto à suscetibilidade à ferrugem alaranjada. Para a formação dos grupos, adotou-se como medida de dissimilaridade a distância euclidiana, e para identificar e reunir grupos homogêneos, utilizou-se o método da Média Aritmética Não-ponderada (UPGMA), que utiliza a distância média do grupo e apresenta os agrupamentos na forma de dendrograma (JOHNSON; WICHERN, 1998).

Para o experimento em casa-de-vegetação, foram calculados, nas três datas de avaliação, a incidência média da doença e a média e o erro padrão da severidade para cada folha da planta.

\section{RESULTADOS E DISCUSSÃO}

\section{Avaliação da reação de cultivares em campo}

Dentre as 28 cultivares de cana-de-açúcar avaliadas, 14 foram suscetíveis à ferrugem alaranjada (Tabela 1). O restante foi considerado resistente à doença.

Houve diferença entre as médias das cultivares em todas as datas (Tabela 1), mas considera-se que a AACPD se constitui no critério de diferenciação mais seguro, pois é calculada a partir de vários pontos de avaliação e, portanto, permite uma avaliação mais estável, sendo menos afetado pelo tempo de análise e flutuações ambientais (CAMPBELL; MADDEN, 1990).

Pelos dados de AACPD obtidos, a cultivar RB72454 foi considerada a mais suscetível à doença (Tabela 1). As demais cultivares foram diferenciadas em cinco classes de suscetibilidade. A cultivar RB956911 se mostrou como a segunda cultivar mais suscetível à doença. No entanto, sua $\operatorname{AACPD}(2,134)$ foi muito inferior àquela calculada para a $\operatorname{RB72454}(10,202)$, o que ressalta a alta suscetibilidade desta cultivar à ferrugem alaranjada. Um terceiro nível de suscetibilidade foi representado pela cultivar RB925345. As cultivares RB835486, RB855035, RB925211, RB845197, RB785148 e RB966229 foram diferenciadas num quarto nível e a cultivar RB855156 constituiu um quinto nível de suscetibilidade. A última classe, que representou o menor nível de suscetibilidade à ferrugem alaranjada, foi formada pela cultivares RB986419, RB835054, RB835036 e RB865230.

Tabela 1. Médias de severidade da ferrugem alaranjada (Puccinia kuehnii), em cana-planta e cana-soca, e Área Abaixo da Curva de Progresso da Doença (AACPD), em cana-soca, de cultivares de cana-de-açúcar (Saccharum spp.) plantadas no Estado do Paraná. 


\begin{tabular}{|c|c|c|c|c|c|c|}
\hline \multirow[b]{2}{*}{ Cultivar } & \multirow{2}{*}{$\begin{array}{l}\text { Cana-planta } \\
10 \text { meses } \\
(\mathrm{Jul} / 11)\end{array}$} & \multicolumn{4}{|c|}{ Cana-soca } & \multirow{2}{*}{$\begin{array}{l}\text { AACPD em } \\
\text { cana-soca }^{(1)}\end{array}$} \\
\hline & & $\begin{array}{c}3 \text { meses } \\
(\text { Nov/11) }\end{array}$ & $\begin{array}{l}5 \text { meses } \\
(\mathrm{Jan} / 12)\end{array}$ & $\begin{array}{c}7 \text { meses } \\
(\mathrm{Mar} / 12)\end{array}$ & $\begin{array}{l}9 \text { meses } \\
(\mathrm{Mai} / 12)\end{array}$ & \\
\hline RB72454 & $9,370 \mathrm{a}$ & $0,117 \mathrm{~d}$ & $4,052 \mathrm{a}$ & $8,607 \mathrm{a}$ & $29,600 \mathrm{a}$ & $10,202 \mathrm{a}$ \\
\hline RB956911 & $0,000 \mathrm{f}$ & $0,440 \mathrm{c}$ & $6,017 \mathrm{a}$ & $0,050 \mathrm{~b}$ & $0,610 \mathrm{c}$ & $2,134 \mathrm{~b}$ \\
\hline RB925345 & $0,016 \mathrm{f}$ & $2,522 \mathrm{a}$ & $1,690 \mathrm{~b}$ & $1,080 \mathrm{~b}$ & $0,532 \mathrm{c}$ & $1,341 \mathrm{c}$ \\
\hline RB835486 & $0,441 \mathrm{c}$ & $3,070 \mathrm{a}$ & $0,422 \mathrm{c}$ & $0,495 \mathrm{~d}$ & $0,090 \mathrm{~d}$ & $0,659 \mathrm{~d}$ \\
\hline RB855035 & $0,041 \mathrm{e}$ & $1,112 b$ & $0,900 \mathrm{~b}$ & $0,052 \mathrm{~d}$ & $0,345 \mathrm{c}$ & $0,534 \mathrm{~d}$ \\
\hline RB925211 & $0,650 \mathrm{c}$ & $0,031 \mathrm{e}$ & $0,215 \mathrm{~d}$ & $0,245 \mathrm{~d}$ & $1,770 \mathrm{~b}$ & $0,515 \mathrm{~d}$ \\
\hline RB845197 & $1,230 \mathrm{~b}$ & $0,878 \mathrm{~b}$ & $0,435 \mathrm{e}$ & $0,127 \mathrm{~d}$ & $1,225 \mathrm{~b}$ & $0,460 \mathrm{~d}$ \\
\hline RB785148 & $0,225 \mathrm{~d}$ & $0,018 \mathrm{e}$ & $0,085 \mathrm{e}$ & $0,272 \mathrm{c}$ & $1,635 \mathrm{~b}$ & $0,456 \mathrm{~d}$ \\
\hline RB966229 & $0,083 \mathrm{e}$ & $0,840 \mathrm{~b}$ & $0,737 \mathrm{~b}$ & $0,035 \mathrm{~d}$ & $0,137 \mathrm{~d}$ & $0,393 \mathrm{~d}$ \\
\hline RB855156 & $0,066 \mathrm{e}$ & $0,003 \mathrm{f}$ & $0,062 \mathrm{e}$ & $0,060 \mathrm{~d}$ & $0,027 \mathrm{e}$ & $0,044 \mathrm{e}$ \\
\hline RB986419 & $0,000 \mathrm{f}$ & $0,000 \mathrm{f}$ & $0,000 \mathrm{f}$ & $0,001 \mathrm{e}$ & $0,021 \mathrm{e}$ & $0,005 \mathrm{f}$ \\
\hline RB835054 & $0,002 \mathrm{f}$ & $0,000 \mathrm{f}$ & $0,000 \mathrm{f}$ & $0,000 \mathrm{e}$ & $0,013 \mathrm{e}$ & $0,004 f$ \\
\hline RB835036 & $0,000 \mathrm{f}$ & $0,000 \mathrm{f}$ & $0,000 \mathrm{f}$ & $0,000 \mathrm{e}$ & $0,006 \mathrm{e}$ & $0,001 \mathrm{f}$ \\
\hline RB865230 & $0,016 \mathrm{f}$ & $0,000 \mathrm{f}$ & $0,000 \mathrm{f}$ & $0,000 \mathrm{e}$ & $0,002 \mathrm{e}$ & $4,11 \times 10^{-4} \mathrm{f}$ \\
\hline $\mathrm{CV}(\%)$ & 13,69 & 8,78 & 10,42 & 14,85 & 11,31 & 12,64 \\
\hline
\end{tabular}

Dados originais, sem transformação; médias seguidas da mesma letra, na coluna, não diferem significativamente entre si pelo teste de Scott-Knott, ao nível de $5 \%$ de probabilidade; ${ }^{(1)}$ AACPD em cana-soca relativa por dia.

Apesar de a AACPD ser o melhor critério de diferenciação das cultivares, deve-se considerar que para sua obtenção, um período de tempo relativamente longo para avaliações é requerido, o que, na prática, nem sempre é possível. A fim de simplificar esse trabalho, buscou-se a data de avaliação que mais se correlacionou com a AACPD (Tabela 2).

Tabela 2. Correlação de Pearson entre os resíduos de cada data de avaliação da severidade da ferrugem alaranjada (Puccinia kuehnii), em cana-planta e cana-soca, e da Área Abaixo da Curva de Progresso da Doença (AACPD), em cana-soca.

Correlação de Pearson (valor de $p$ )

\begin{tabular}{ccccccc}
\cline { 2 - 7 } Avaliações & AACPD & $\begin{array}{c}\text { Cana-planta } \\
10 \text { meses } \\
(\mathrm{jul} / 2011)\end{array}$ & $\begin{array}{c}\text { Cana-soca } \\
3 \text { meses } \\
(\text { nov/2011) }\end{array}$ & $\begin{array}{c}\text { Cana-soca } \\
5 \text { meses } \\
(\mathrm{jan} / 2012)\end{array}$ & $\begin{array}{c}\text { Cana-soca } \\
7 \text { meses } \\
(\mathrm{mar} / 2012)\end{array}$ & $\begin{array}{c}\text { Cana-soca } \\
9 \text { meses } \\
(\mathrm{mai} / 2012)\end{array}$ \\
\hline \multirow{2}{*}{ AACPD } & 1,0000 & $\begin{array}{c}0,0003 \\
(0,9978)\end{array}$ & $\begin{array}{c}0,3140 \\
(0,0184)\end{array}$ & $\begin{array}{c}0,2753 \\
(0,0399)\end{array}$ & $\begin{array}{c}0,0082 \\
(0,9520)\end{array}$ & $\begin{array}{c}0,6419 \\
\left(9,72 \times 10^{-8}\right)\end{array}$ \\
\hline
\end{tabular}

*nível de significância de $\mathrm{p}<0,05$.

As avaliações feitas em cana-planta, aos dez meses, em meados de julho, e, em cana-soca, aos sete meses, em março, não apresentaram correlação com a AACPD, ao nível de 5\% de probabilidade (Tabela 2).

As avaliações em cana-soca, aos três e cinco meses, no mês de novembro e janeiro, respectivamente, apresentaram uma correlação significativa com a AACPD (Tabela 2). No entanto, essa correlação foi baixa $(0,3140$ e 0,2753 , respectivamente).

A avaliação em cana-soca, aos nove meses, que ocorreu em maio, apresentou a melhor correlação com a AACPD $\left(0,6419 ; p=9,72 \times 10^{-8}\right)$ (Tabela 2), o que estabeleceu que dentre as épocas de avaliação testadas, esta foi a mais adequada para classificar cultivares quanto a sua suscetibilidade à ferrugem alaranjada na região norte do Estado do Paraná.

O dendrograma referente à análise de agrupamento da variável severidade nas diferentes datas de avaliação está representado na figura 1 . Os 14 genótipos suscetíveis foram distribuídos em quatro grupos tendo-se considerado como ponto de corte a distância euclidiana de $25 \%$. 


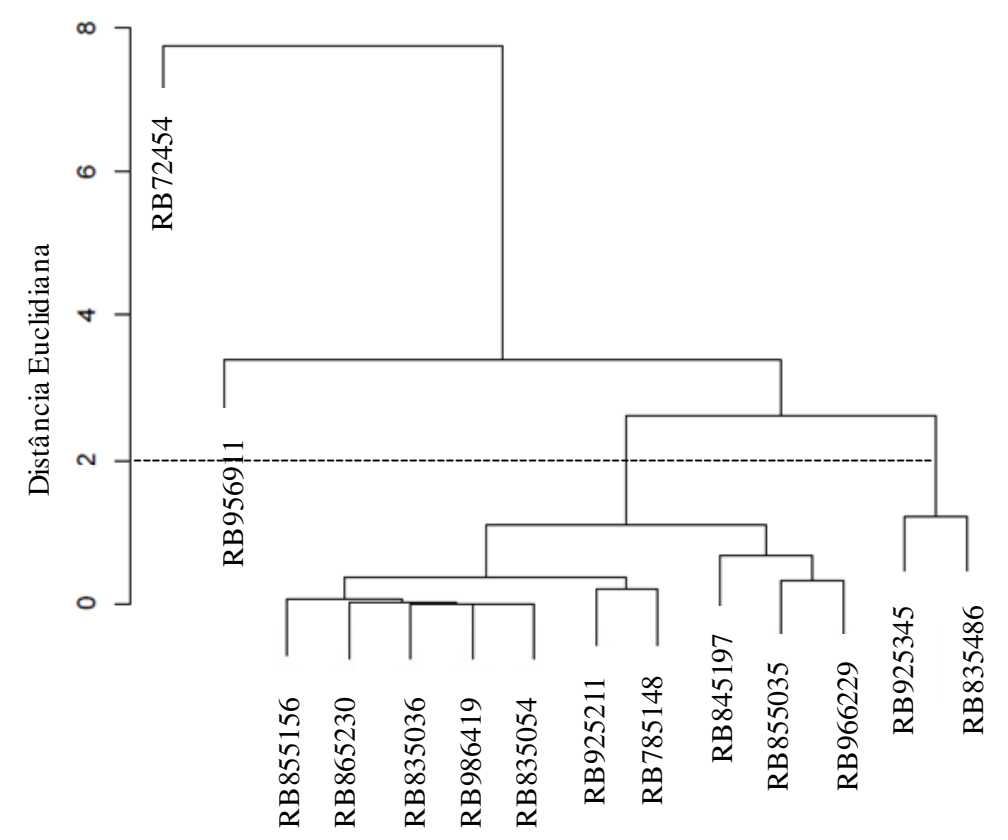

Cultivar

Figura 1. Dendrograma resultante da análise de agrupamento de 14 genótipos de cana-de-açúcar (Saccharum spp.) com base em valores médios de severidade da ferrugem alaranjada (Puccinia kuehnii), nas avaliações em cana-planta, dez meses, e cana-soca, três, cinco, sete e nove meses.

O grupo I foi formado pela cultivar RB72454, considerada a mais suscetível à doença (Figura 1). O grupo II foi constituído pela cultivar RB956911. O terceiro grupo foi formado pelas cultivares RB925345 e RB835486 e, as demais cultivares formaram um quarto grupo. Com base nesse agrupamento, sugere-se que o quarto grupo foi constituído das cultivares com maior resistência quantitativa à ferrugem alaranjada. Sugere-se que as cultivares que formaram os grupos II e III, tem resistência parcial menor, apresentando maior suscetibilidade. A cultivar RB72454 é a mais suscetível à doença dentre as cultivares avaliadas, fato esse facilmente observado no campo. No entanto, mais estudos, envolvendo diferentes ciclos de avaliação, são necessários para se inferir com maior segurança sobre a resistência quantitativa destas cultivares.

As cultivares consideradas resistentes à $P$. kuehnii também podem ser divididas em dois grupos. Um grupo é formado por aquelas cultivares que não apresentaram nenhum sintoma da doença no decorrer das avaliações (RB966928, RB835089, RB845210, RB845257, RB855546, RB855113, RB867515, RB925268, RB928064, RB835744 e RB92579). Outro grupo é formado pelas cultivares nas quais se encontrou sintoma na forma de pústula em determinada avaliação, porém em intensidade insignificante para estimativa de severidade. Estas cultivares foram: RB946903, RB855536, RB855453. Para as cultivares classificadas como resistentes, há de se considerar a possibilidade de manifestação da doença em condições de maior pressão do inóculo. Genótipos resistentes podem se tornar susceptíveis no tempo devido à variabilidade da população do patógeno (Braithwaite et al., 2009).

Trabalhos avaliando a reação de cultivares de cana-de-açúcar à ferrugem alaranjada no Brasil ainda são escassos. Em trabalho desenvolvido por Ruas et al. (2010), no município de Jaboticabal-SP, testando a reação de algumas cultivares à doença, classificou-se a cultivar RB72454 como suscetível à ferrugem alaranjada e a RB867515 como resistente, resultado que corrobora o encontrado neste trabalho. Araújo et al. (2010), avaliando a favorabilidade genotípica para ocorrência da ferrugem alaranjada, no município de Valparaíso-SP, afirmaram que as cultivares RB72454, RB855156 e RB925211 foram suscetíveis à doença, assim como encontrou-se neste trabalho desenvolvido em Paranavaí-PR. No entanto, os autores também afirmaram terem encontrado sintomas da doença na cultivar RB92579, a qual se mostrou resistente neste trabalho. Possivelmente, essa reação de 
suscetibilidade da cultivar RB92579 foi devida à maior pressão de inóculo presente no trabalho desenvolvido em Valparaíso, pois entre cada parcela experimental foi incluído um sulco de cinco metros de comprimento da cultivar suscetível CV14, que atuou como doadora de urediniósporos.

O comportamento diferenciado das cultivares no decorrer das avaliações sugere que o progresso da doença não está apenas relacionado ao estádio fenológico e à época do ano, mas é altamente dependente da interação entre genótipo $\mathrm{x}$ ambiente. Com uma alta severidade, a cultivar RB72454 pode ser considerada um padrão suscetível à ferrugem alaranjada. Sua reação segue o determinado por Magarey (2000), quando afirmou que a maiores severidades da doença ocorrem a partir do meio do ciclo da cultura até a sua maturação. As outras cultivares, por terem uma suscetibilidade intermediária à $P$. kuehnii, não apresentaram um comportamento típico no decorrer das estações.

\section{Avaliação da cultivar padrão suscetível em condições controladas}

KLOSOWSKI, A. C.

Sete dias após a inoculação (DAI), verificou-se o aparecimento de "flecks" em mais de 50\% das plantas avaliadas da cultivar RB72454, que se caracterizam como pontuações cloróticas antecedentes ao aparecimento das pústulas. Os "flecks" se constituíram nos primeiros sintomas e seu aparecimento determinou o período de incubação da doença.

No $10^{\circ}$ dia foi observado o aparecimento das pústulas em mais de $50 \%$ das plantas avaliadas. A esporulação também ocorreu aos 10 DAI, ou seja, as lesões já apareceram esporulando, caracterizando o período de latência para a cultivar suscetível sob condições ideais para o desenvolvimento da doença.

$\mathrm{Na}$ primeira avaliação, a incidência foi de $56 \%$, ou seja, aproximadamente metade das folhas de cada planta apresentou lesões (Tabela 3). Destas, merecem destaque a folha +2 e 0 , que apresentaram pústulas em aproximadamente $80 \%$ das plantas avaliadas, seguidas da folha +1 , que apresentou pústulas em aproximadamente $70 \%$ das plantas avaliadas.

Tabela 3. Incidência (\% de folhas com sintomas em relação ao $n^{\circ}$ total de folhas) e severidade ( $\mathrm{n}^{\circ}$ de pústulas na área de $5 \mathrm{~cm}^{2}$ ) da ferrugem alaranjada (Puccinia kuehnii) nas diferentes folhas da cana-de-açúcar (Saccharum spp.), cultivar RB72454, em três datas de avaliação em casa-de-vegetação.

\begin{tabular}{|c|c|c|c|c|c|c|c|c|}
\hline \multirow{3}{*}{ Avaliação } & \multirow{3}{*}{ Incidência (\%) } & \multicolumn{7}{|c|}{ Severidade ( $\mathrm{n}^{\circ}$ de pústulas) } \\
\hline & & \multicolumn{6}{|c|}{ Folha } & \multirow{2}{*}{ Média } \\
\hline & & +4 & +3 & +2 & +1 & 0 & -1 & \\
\hline $10 \mathrm{DAI}$ & $56,0( \pm 3,8)$ & $12,8( \pm 6,2)$ & $14,2( \pm 9,8)$ & $11,7( \pm 4,3)$ & $12,8( \pm 8,0)$ & $42,5( \pm 9,9)$ & $5,4( \pm 4,5)$ & $16,6( \pm 5,5)$ \\
\hline $15 \mathrm{DAI}$ & $85,6( \pm 2,4)$ & $33,3( \pm 11,9)$ & $49,5( \pm 19,6)$ & $42,7( \pm 15,8)$ & $50,3( \pm 27,7)$ & $100,9( \pm 13,9)$ & $14,6( \pm 8,4)$ & $48,5( \pm 12,2)$ \\
\hline $20 \mathrm{DAI}$ & $88,7( \pm 3,4)$ & $37,8( \pm 13,3)$ & $73,7( \pm 19,3)$ & $57,5( \pm 19,7)$ & $68,1( \pm 29,3)$ & $120,9( \pm 18,1)$ & $15,7( \pm 9,2)$ & $62,3( \pm 15,2)$ \\
\hline
\end{tabular}

DAI = dias após a inoculação. Valores de severidade em negrito foram estimados com base em tamanho de lesões; demais valores foram contados.

$\mathrm{Na}$ segunda avaliação, a incidência da doença aumentou para 85,6\% (Tabela 3), indicando que houve um aumento de $34,5 \%$ de folhas doentes nos cinco dias decorrentes entre as avaliações.

$\mathrm{Na}$ terceira avaliação, verificou-se que a incidência absoluta foi inferior à encontrada na segunda avaliação, possivelmente devido ao modo de crescimento da cana-de-açúcar. No momento da inoculação, havia uma média de cinco folhas abertas nas plantas e, no decorrer das avaliações, folhas novas foram emitidas a partir do cartucho sendo que, na terceira avaliação, a média de folhas por planta foi de sete folhas. A folha -1, que estava no cartucho no momento da inoculação, apresentou sintomas em aproximadamente $19 \%$ das plantas e a folha -2 , que foi emitida mais tarde, não apresentou sintomas em nenhuma planta no período avaliado. Neste período do monociclo, os sintomas são decorrentes dos contatos efetivos dos urediniósporos com o tecido da planta no momento da inoculação. No entanto, é provável que a folha -2 e as demais folhas que estavam no cartucho no momento da inoculação, venham a apresentar sintomas decorrentes dos ciclos secundários do patógeno. Por esse motivo, a incidência absoluta se tornou um parâmetro pouco expressivo, de modo que, considerando-se uma incidência relativa ao número de folhas que estavam passíveis de receber o 
inóculo, pode-se considerar que esta foi de $88,7 \%$ (Tabela 3), representando que aproximadamente 3\% de folhas que não apresentavam sintomas aos 15 DAI, passaram a apresentá-los aos 20 DAI.

A maior incidência de pústulas foi observada na parte abaxial da folha, encontrando-se, no entanto, algumas pústulas também na parte adaxial, o que está de acordo com o encontrado por Magarey (2000), Infante et al. (2009) e Martins (2010). Embora não se tenha conhecimento exato sobre a penetração deste fungo, a maior quantidade de estômatos presente na face abaxial da folha da cana-de-açúcar (James, 2004) pode indicar que a infecção ocorra por meio destes.

Na primeira avaliação, o número médio de pústulas encontradas na área demarcada foi de aproximadamente 16 pústulas (Tabela 3 ). $\mathrm{Na}$ segunda avaliação, o número médio de pústulas contabilizadas por folha foi de aproximadamente 48 .
Portanto, o número de lesões aumentou de forma significativa nos cinco dias decorridos.

$\mathrm{Na}$ última avaliação, realizada aos 20 DAI, o método de contagem de pústulas foi dificultado pelo coalescimento das lesões (Figura 2). Apenas nas folhas +4 e -1 conseguiu-se fazer a contagem, pois estas folhas apresentavam menor severidade da doença e, portanto, suas pústulas não haviam coalescido. Nas demais, estimou-se um número próximo ao real, com base no tamanho das pústulas observado nas folhas com lesões não agrupadas. Desse modo, estimou-se que havia uma média de 62 pústulas por folha.

A folha 0 apresentou maior número de pústulas em todas as avaliações. Sugere-se que no momento da inoculação pode ter havido um acúmulo da suspensão em contato com esta folha, que não estava totalmente aberta, com parte dela ainda enrolada no cartucho, e, portanto, pode ter retido mais o inóculo que as demais folhas.
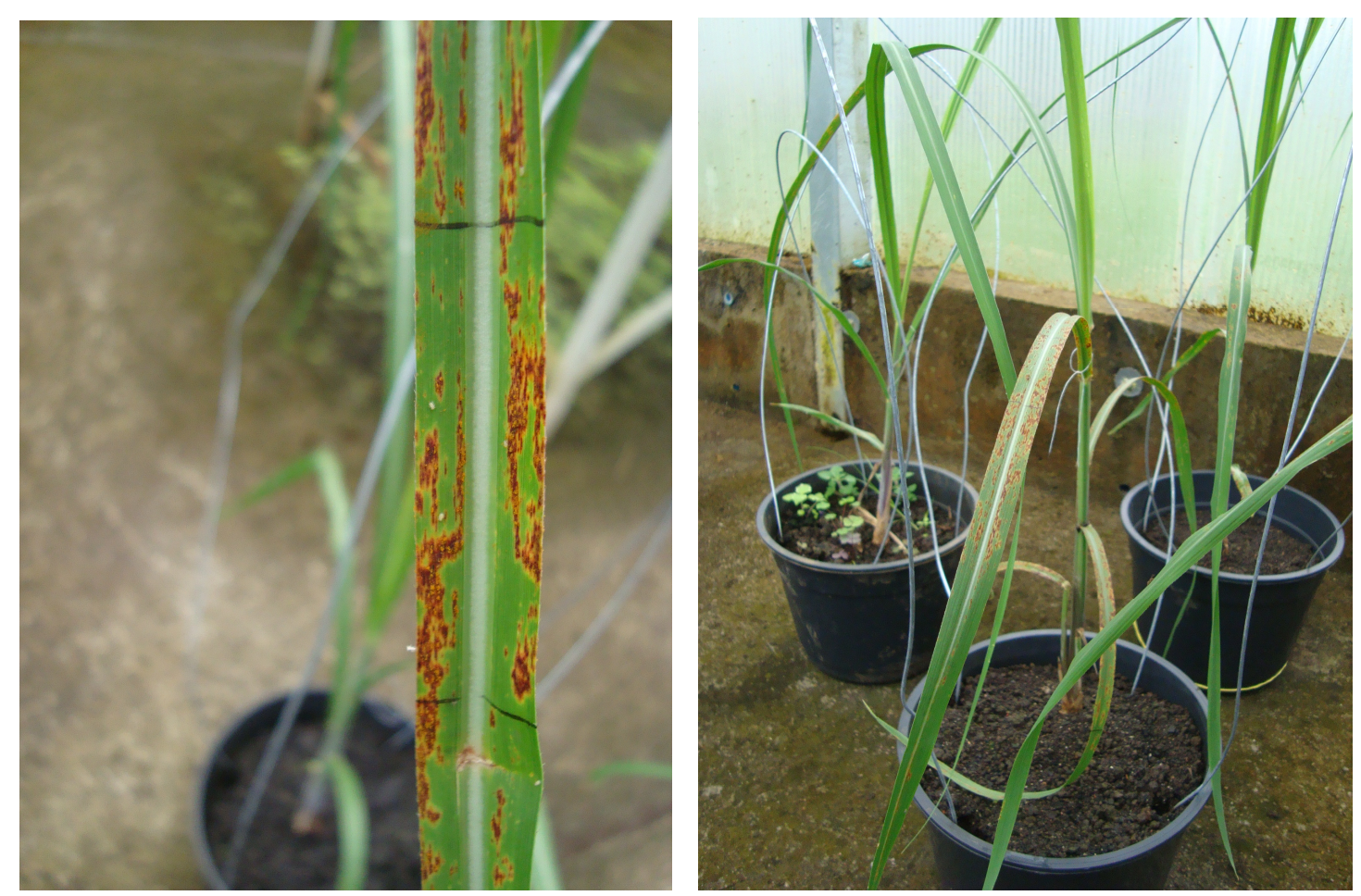

Figura 2. Severidade da ferrugem alaranjada (Puccinia kuehnii) em folhas de cana-de-açúcar (Saccharum spp.), da cultivar RB72454, aos 20 dias após a inoculação.

A coalescência das pústulas aos 20 DAI merece destaque, pois em trabalho semelhante desenvolvido na Flórida, Martins (2010), inoculando a cultivar CL 85-1040 com uma suspensão na concentração de $1 \times 10^{5}$ urediniósporos. $\mathrm{mL}^{-1}$, realizou a avaliação de severidade de $P$. kuehnii através de contagem das pústulas até observar sua estabilidade, o que ocorreu aproximadamente 30 dias após a inoculação. No período avaliado, os dados apresentados assim como as fotos dos sintomas, tornaram evidente a baixa severidade da doença com relação ao que foi encontrado neste trabalho. Estas constatações levaram a concluir que o desenvolvimento da doença está condicionado por diversos fatores, dentre eles a cultivar de cana-de-açúcar e sua suscetibilidade à doença, o inóculo e sua 
agressividade, além das condições de temperatura e umidade propícias ao desenvolvimento da doença.

Para melhor entendimento dos componentes monocíclicos da ferrugem alaranjada, devem-se fazer avaliações diárias de severidade. As folhas +3 e/ou +1 podem ser recomendadas para este fim, pois se comportaram de forma semelhante em relação à doença e apresentaram incrementos de severidade próximos no decorrer das avaliações, se mostrando adequadas na avaliação do monociclo da ferrugem alaranjada.

\section{CONCLUSÕES}

Dentre as cultivares avaliadas, 14 são consideradas suscetíveis à ferrugem alaranjada, podendo ser divididas em quatro grupos de suscetibilidade, sendo que a cultivar RB72454 se apresenta como padrão suscetível à doença.

As avaliações no mês de maio são mais adequadas para os programas de melhoramento avaliarem a reação de cultivares à ferrugem alaranjada na região norte do Estado do Paraná.

Em condições controladas, os períodos de incubação e latência do fungo $P$. kuehnii na cultivar padrão suscetível foram de sete e dez dias, respectivamente. Aos 20 DAI, a incidência da doença foi de aproximadamente $90 \%$ das folhas e as lesões já estavam coalescidas na maioria das folhas.

\begin{abstract}
The aims of this study were to assess the reaction of 28 sugarcane cultivars to orange rust, establishing the most appropriate date for the breeding programs assess the reaction of cultivars, and, in greenhouse, determine the incubation and latency periods, the incidence and the severity in the susceptible standard cultivar. In the field, the severity was assessed in plant cane (ten months) and ratoon crops (three, five, seven and nine months). The area under the disease progress curve (AUDPC) was calculated from these data. To establish the appropriate date of assessment, the Pearson correlation was calculated between the residues of assessment dates and the AUDPC. In greenhouse, the cultivar RB72454 was inoculated and the incidence and severity were assessed. Among 28 cultivars, 14 showed some degree of susceptibility of orange rust and they may be discriminated into four groups of susceptibility. The assessment in May was the most correlated with AUDPC, being the appropriate date for assessing susceptibility of cultivars to orange rust, in the northern region of Paraná State. The incubation and latency periods in the susceptible standard cultivar were seven and ten days, respectively. The cultivar RB72454 is the only highly susceptible to orange rust and other cultivars assessed have lower degrees of susceptibility.
\end{abstract}

KEYWORDS: Puccinia kuehnii. Saccharum spp.. Susceptibility levels. Assessment date. Incubation. Latency.

\title{
REFERÊNCIAS
}

ARAÚJO, K. L.; GILIO, T. A. S.; SANCHES, P. R. B.; NEUBAUER, R. A.; FAGUNDES, C.; BASSAN, B. E.; RODERO, D. P.; RODERO, D. C. P.; GIGLIOTI, E. A.; CANTERI, M. G. Monitoramento da favorabilidade genotípica para ocorrência da ferrugem alaranjada da cana-de-açúcar no Brasil. In: CONGRESSO BRASILEIRO DE FITOPATOLOGIA, XLIV, 2011, Bento Gonçalves. Tropical Plant

Pathology. Brasília: Associação Brasileira de Fitopatologia, 2011. v. 36 (suplemento). p. 839. Cd-rom.

BARBASSO, D.; JORDÃO, H.; MACCHERONI, W.; BOLDINI, J.; BRESSIANI, J.; SANGUINO, A. First report of Puccinia kuehnii, causal agent of orange rust of sugarcane, in Brazil. Plant Disease, St. Paul, v. 94, n. 9, p. 1170, 2010.

BOX, G. E. P.; COX, D. R. An analysis transformation. Journal of the Royal Statistical Society, London, Série B, v. 26, n. 2, p. 211-252, 1964.

BRAITHWAITE, K. S.; CROFT, B. J.; MAGAREY, R. C.; SCHARASCHKIN, T. Phylogenetic placement of the sugarcane orange rust pathogen Puccinia kuehnii in a historical and regional context. Australasian Plant Pathology, Queensland, v. 38, n. 4, p. 380-388, 2009. http://dx.doi.org/10.1071/AP09012

CAMPBELL, C. L.; MADDEN, L. V. Introduction to plant disease epidemiology. New York: John Wiley, 1990. 532p. 
CONAB - COMPANHIA NACIONAL DE ABASTECIMENTO. Acompanhamento de safra brasileira: Cana-de-açúcar, primeiro levantamento abril, 2012. Brasília: Companhia Nacional de Abastecimento, 2012. 15p. Disponível em: http://www.conab.gov.br/OlalaCMS/uploads/arquivos/ 12_04_10_09_19_04_boletim_de_cana.pdf. Acesso em: 25 de abr. 2012.

FAO - FOOD AND AGRICULTURE ORGANIZATION OF THE UNITED NATIONS. Base de dados Faostat - Agriculture, 2010. Roma, 2010. Disponível em: <http://faostat.fao.org/site/567/Desktop Default.aspx?PageID=567\#ancor $>$. Acesso em: 12/11/2013.

FEDERIZZI, L. C.; STUTHMAN, D. Porque os genes maiores para resistência à ferrugem da folha tem pouca durabilidade no Brasil. In: REUNIÃO DA COMISSÃO BRASILEIRA DE PESQUISA EM AVEIA, 18., 1998, Londrina. Resumos. Londrina: IAPAR, 1998. p. 1-2.

GAZAFFI, R; OLIVEIRA, K. M.; SOUZA, A. P.; GARCIA, A. A. F. Melhoramento Genético e Mapeamento da Cana-de-açúcar. In: CORTEZ, L.A.B. (Ed.) Bioetanol de Cana-de-açúcar - P\&D para produtividade e sustentabilidade. 1.ed. São Paulo: Blucher, 2010. p. 333-343.

INFANTE, D.; MARTINEZ, B.; GONZALEZ, E.; GONZALEZ, N. Puccinia kuehnii (Kruger) Butler y Puccinia melanocephala H. Sydow y P. Sydow. en el cultivo de la caña de azúcar. Revista Protección Vegetal, La Habana, v. 24, n. 1, p. 22-28, 2009.

JAMES, G. L. An introduction to sugarcane. In: JAMES, G. L. Sugarcane. 2.ed. v. 1. Oxford: Blackwell Science, 2004. p. 1-19. http://dx.doi.org/10.1002/9780470995358.ch1

JOHNSON, R. A.; WICHERN, D. W. Applied multivariate statistical analysis. 4.ed. Upper Saddle River: Prentice Hall, 1998. 816p.

KLOSOWSKI, A. C.; RUARO, L.; BESPALHOK FILHO, J. C.; MAY-DE MIO, L. L. Proposta e validação de escala para a ferrugem alaranjada da cana-de-açúcar. Tropical Plant Pathology, Brasília, v. 38, n. 2, p. 166171, 2013. http://dx.doi.org/10.1590/S1982-56762013000200012

MAGAREY, R. C. Orange rust. In: ROTT, P.; BAILEY, R. A.; COMSTOCK, J. C.; CROFT, B. J.; SAUMTALlY, A. S. A guide to sugarcane diseases. Montpellier: La Librairie du Cirad, 2000. p. 121-125.

MARTINS, T. D. Aspectos epidemiológicos da ferrugem alaranjada da cana-de-açúcar. 2010. 65p. Tese (Doutorado) - Universidade de São Paulo - Escola Superior de Agricultura “Luiz de Queiroz”, São Paulo.

MINCHIO, C. A.; CANTERI, M. G.; ROCHA, J. A. Germinação de uredósporos de Puccinia kuehnii submetidos à diferentes temperaturas e tempos de incubação. Summa Phytopathologica, Botucatu, v. 37, n. 4, p. 211-214, 2011.

PARLEVLIET, J. E. Components of resistance that reduce the rate of epidemic development. Annual Review of Phytopathology, Palo Alto, v. 17, n. 1, p. 203-222, 1979.

http://dx.doi.org/10.1146/annurev.py.17.090179.001223

ROSSETO, R.; SANTIAGO, A. D. Agência de Informação EMBRAPA Cana-de-açúcar: doenças. Brasília: Empresa Brasileira de Pesquisa Agropecuária, 2005. Disponível em: http://www.agencia.cnptia. embrapa.br/gestor/cana-de-acucar/arvore/CONTAG01_55_711200516718.html. Acesso em: 15 de abr. 2011.

RUAS, A. R.; LODO, B. N.; RAMOS, L. R.; SCALOPPI, E. A. G.; BARRETO, M. Reação de genótipos de cana-de-açúcar à ferrugem alaranjada. In: CONGRESSO BRASILEIRO DE FITOPATOLOGIA, XLIII, 2010, Cuiabá. Tropical Plant Pathology. Brasília: Associação Brasileira de Fitopatologia, 2010. v. 34 (suplemento). Cd-rom. 
SANTOS, A. S. Doenças causadas por fungos e bactérias em cana-de-açúcar. Comunicado Técnico. Campinas: Embrapa, 2004. p. 11-17. Disponível em: http://ag20.cnptia.embrapa.br/Repositorio/santos1 _000fxf38vwn02wyiv80soht9h8s4br2p.pdf. Acesso em: 16 de abr. 2011.

SILVA, E. G.; BEDENDO, I. P.; CASAGRANDE, M. V. Ocorrência de fitoplasma associado à síndrome do amarelecimento foliar da cana-de-açúcar em três regiões do Estado de São Paulo. Tropical Plant Pathology, Brasília, v. 33, n. 6, p. 453-456, 2008.

STEEL, R. G. D. et al. Principles and procedures of statistics: a biometrical approach. 3.ed. Boston: McGraw Hill, 1997. 666p.

ZHAO, D.; GLYNN, N. C.; GLAZ, B.; COMSTOCK, J. C.; SOOD, S. Orange rust effects on leaf photosynthesis and related characters of sugarcane. Plant Disease, St. Paul, v. 95, n. 6, p. 640-647, 2011. 